\title{
Approach to Diagnosis of Anemia in Children
}

\author{
M Tawfique ${ }^{1}$, C Y Jamal ${ }^{2}$
}

1 Dr. Muhammad Tawfique Associate Professor Pediatric Hematology \& Oncology Dhaka Shishu(Children) Hospital

${ }^{2}$ Prof. Chowdhury Yakub Jamal Chairman and Professor Pediatric Hematology \& Oncology Bangabandhu Sheikh Mujib Medical University

\section{Correspondence}

Dr. Muhammad Tawfique Associate Professor Pediatric Hematology \& Oncology Dhaka Shishu(Children) Hospital e-mail: mtawfique@gmail.com

\begin{abstract}
Summary
Anemia is the reduction of hemoglobin concentration that can occur in a wide range of disease spectrum. Managing a patient of anemia is in fact diagnosing the cause of anemia and then treating the cause of it accordingly.

This review article covered the discussion on the diagnostic approach of the disorders associated with anemia. As history and physical examination are so important so is too are lab investigations.
\end{abstract}

\section{Introduction}

Anemia can be defined as a reduction in hemoglobin concentration, haematocrit or number of RBC per cubic $\mathrm{mm}$. The lower limit of normal range is set at two standard deviation below the mean for age and sex of the normal population. ${ }^{1}$

Anemia is a widespread public health problem associated with an increased risk of morbidity and mortality, especially in pregnant women and young children. ${ }^{2}$ Globally 1.62 billion people are anemic, while among the preschool children the prevalence of anemia is $47.4 \%$. Nutritional anemia in South Asia accounts for nearly half of global cases of anemia. In India, anemia continues to be the major health problem in young children, adolescent girls, and pregnant women. Approximately $50 \%$ of the population suffers from nutritional anemia as known in countries where meat consumption is low. ${ }^{3}$ In India, about 89 million children are anemic. The prevalence of anemia was $70 \%$ in children aged 6-59 months. ${ }^{4}$

In clinical practice, anemia is one of the most frequently encountered clinical sign. It could be the manifestation of so many diseases. ${ }^{5}$ To go for the diagnosis of anemia the approach should begin right from the commencement of history taking and physical examination and later with the help of laboratory support.

To start clinically the causes are to be considered first. It could be Nutritional, malabsorption, bone marrow dysfunction, bone marrow infiltrative disorders and hemolysis. Therefore, one should be very systematic and judicious in the approach to detect the cause and reach the diagnosis.

\section{The causes of anemia ${ }^{6}$}

I. Decreased production of erythrocytes:

a. Iron deficiency anemia

b. Copper deficiency

c. Megaloblastic anemia

d. Pyridoxine deficiency

e. Hypoplastic and aplastic anemia

i. Congenital hypoplastic anemia

ii. Transient erythroblastopenia in childhood

iii. Fanconi anemia

iv. Osteopetrosis

v. Aplastic crisis in hemolytic anemia

vi. Aplastic anemias

f. Marrow infiltration in leukemia, neuroblastoma, or granuloma

g. Congestive splenomegaly, Gaucher Disease

h. Hypothyroidism

i. Lead poisoning

j. Chronic Renal Disease

k. Acute Infections or inflammation

I. Chronic disease

m. Hemophagocytic syndrome

n. Sideroblastic anemia

o. Congenital atransferrinemia

p. Immunocompromised patients

II. Increased destruction of erythrocytes:

a. Erythrocyte membrane defects

i. Hereditary spherocytosis

ii. Hereditary Elliptocytosis 
iii. Infantile pyknocytosis, Pyropoikilocytosis

iv. Hereditary stomatocytosis

v. Paroxysmal nocturnal hemoglobinuria

vi. Erythropoietic Porphyria

vii. Abetalipoproteinemia

b. Hemoglobinpathies

i. Sickle cell $\mathrm{Hb}$ disorders

ii. Thalassemia syndromes

iii. Unstable Hbs

iv. Hereditary persistence of fetal $\mathrm{Hb}$

c. Hereditary enzyme defects of erythrocytes

i. Defects of Embden-Meyerhof pathway

ii. Defects of Hexose Monophosphate shunt

iii. Defects of glutathione synthesis

iv. Abnormalities of erythrocyte nucleotide metabolism

d. Extra corpuscular mechanisms

i. Immune hemolytic anemia

ii. Non-immune hemolytic anemia

\section{Blood loss}

\section{The genesis of anemia}

Different disorders lead to different kind of events and disruption of normal activities and homeostasis of the body. As $\mathrm{Hb}$ and RBCs are in the central stage of anemia the stuffs required for the synthesis of $\mathrm{Hb}$ and RBCs, if remain deficient, cause deficiency anemias. Therefore, whenever there are deficiency of iron, folic acid, vitamins like cyanocolbalamin, pyridoxine, vitamin C, copper and others, it lead to inadequate synthesis of $\mathrm{Hb}$ causing reduction of $\mathrm{Hb}$ and anemia.The above mentioned factors are found deficient in case of nutritional deficiencies, poor intake, chronic or recurrent diarrhea, malabsorptions, congenital structural Gastro-intestinal disorders, or some post surgical conditions or reparative surgeries. Therefore, these finally lead to poor absorption of the stuffs required for $\mathrm{Hb}$ synthesis or cell membrane integrity of RBCs leading to anemia.7

There can be hemorrhage, acute or chronic ones, those also lead to disorders of anemia. Acute bleeding resulting in anemia is usually profuse. The chronic ones usually are minute and sometimes unrecognisable in naked eyes. In these conditions, if blood is not replaced or transfused, lead to anemia. ${ }^{8}$

Anemia almost invariably accompanies the diagnosis of Acute Leukemias in children and is considered to be one of the most common clinical complications of the disease. In addition a low hemoglobin level is often responsible for fatigue when other associated symptoms usually point out to the cause. As a result decline in quality of life of these children becomes notable. The contributing factors likely are overcrowding of the marrow by malignant cells or blasts, coexisting infections and nutritional deficits. ${ }^{9}$ Similarly, in Lysosomal Storage disorders crowding of the bone marrow spaces affect RBC production and results in anemia. $^{10}$

Anemia also is produced when bone marrow spaces become hypoplastic or aplastic. It can affect all the precursors like erythroid, myeloid and megakaryocytic or it can only affect the erythroid ones. Consequently anemia occurs on account of low RBC productions. These conditions can occur due to direct insult to the stem cells or the supportive structures or the damage to the environment of marrow spaces required for hemopoiesis. As discussed before these can be either due to the effects of drugs, chemicals, virus infections, or due to immunologic responses to any molecule or any adverse event. Besides these acquired conditions Aplastic or hypoplastic anemiacan also be primary or idiopathic. ${ }^{11}$ Occasionally they are associated with some congenital syndromes related to chromosomal or genetic abnormalities. ${ }^{12}$

The anemia resulting from abnormal or excessive or undesired breakdown of RBCs cause reduction of RBC number and thereby causes hemolytic anemia This can be hereditary, or it can be acquired. Hereditary causes related to cell membrane abnormalities or $\mathrm{Hb}$ abnormalities or enzyme make RBCs more susceptible to hemolysis in the spleen or extravascular spaces. These breaking down of RBCs release the haem from $\mathrm{Hb}$ into circulation and causes increase in haem metabolites like bilirubin and as a result hyperbilirubinemia occurs. ${ }^{13}$ To compensate for this deficiency increased demand of $\mathrm{Hb}$ is created and there are medullary and extra-medullary hyperplasia causing some evident structural deformities in the face and enlargement of liver and spleen. The iron gathered from relentless hemolysis are accumulated in the body in its different organs and also leads to increased morbidities and cause mortalities. ${ }^{13}$

In case of hereditary Enzyme deficiency disorders, red cells are broken in the circulation and evoke a different kind of sequence of events. These conditions do occur in challenges by some foods, infections (viral or bacterial) and drugs. Intravascular hemolysis are usually acute and consequences are anemia, hyperbilirubinemia, bilirubinuria, hemoglobinuria and black water urine. ${ }^{14}$ On the other hand because of attaching $\mathrm{Hb}$ to albumin, hemopexin and haptoglobin it results in hypoalbuminemia and low haptoglobin levels. There are other acquired conditions when RBCs undergo some mechanical stress having wear and tears inflicted to their cell walls during circulation causing RBC lysis and anemia. Additionally, some immune conditions also cause red cell break down either by antibodies or complement mediated actions when intravascular hemolysis occurs leading to similar events as mentioned in other intravascular causes of hemolysis. In case of hemolysis, intravascular or extravascular, immune or nonimmune, acquired or genetic, some 
compensatory physiological responses lead to increased activities of bone marrow and the other parts of reticuloendothelial system. ${ }^{15}$

\section{The history to be covered}

The history should be taken as when the disease was started or for how long the anemia has been for to identify if it is an acute or a chronic disease or if it is a congenital or acquired disorder. This history can enable us to detect the hereditary anemias like Thalassemia and other RBC cell membrane disorders. Some hypoplastic anemias of congenital causes (Diamond Blackfan anemia), with or without dysmorphism (like Fanconi's anemia), with or without congenital anomalies (Fanconi's anemia, TAR syndrome) can be detected. The above mentioned causes are all chronic causes. There can be some acquired hypoplastic bone marrow related causes which can present as acute or chronic disorders. There can be some acute causes of anemias e.g Autoimmune Hemolytic Anemia and alloimmune hemolytic anemia, acute leukemias. History of fever and association with bleeding disorders could be important clues in the history to diagnose the cause of anemia. ${ }^{16,17}$

\section{The findings associated with anemia}

Having finished history, the most important thing for a clinician is collecting the clinical findings through physical examination. The anemia and its severity should be noted first for the idea about the status.

A rapidly developing severe anemia is likely to give rise to heart failure. On the other hand, severe anemia that developed over a period of months or years is much less likely to give rise to dyspnea or heart failure. There can be facial dysmorphism for the medullary hyperplasia giving the characteristic impression of Hereditary Hemolytic Anemia with failure to thrive usually associated with it. In those cases jaundice and hepatosplenomegaly are likely findings. Jaundice and splenomegaly or hepatosplenomegaly can be associated with anemia in acute hemolysis like Enzyme deficiency or Autoimmune Hemolytic Anemia. All of these patients are usually afebrile.

Hepatosplenomegaly with fever can be due to Acute Leukemia, Non Hodgkin's Lymphoma (NHL), Malaria and Kala-azar and rarely Hodgkin's disease. Hepatosplenomegaly and lymphadenopathy can give rise to the suspicion for Histiocytosis and Tuberculosis but anemia of severe degree is not expected in these diagnoses.

Another important aspect is Anemia without organomegaly, if with fever and cutaneous or mucosal hemorrhage Hypoplastic
Anemia and without fever and Hemorrhage Nutritional anemia are to be considered. Although blood loss anemia should not cause hepatosplenomegaly yet GastroIntestinal bleeding from Portal Hypertension can give rise to blood loss anemia with splenomegaly and sometimes hepatomegaly pretty much like Hereditary Hemolytic Anemia. ${ }^{16,17}$

\section{The lab investigations in anemia}

For estimations of Anemia $\mathrm{Hb}$ and a complete hemogram are required. This can give us the ideas about the severity of anemia as well as the type of anemia from RBC indices like Mean Corpuscular Volume (MCV), Mean Corpuscular Hemoglobin (MCH), Mean Corpuscular Hemoglobin Concentration (MCHC) and Red Cell Distribution Width (RDW). From the RBC indices we can know if the anemia is microcytic, hypochromic, microcytic hypochromic, Macrocytic, normocytic, normochromic or normocytic normochromic. From Red Cell Distribution Width (RDW)we get the knowledge about Anisocytosis. Here, view of Peripheral blood film (PBF) can be conclusive to show the morphology of RBC and can be diagnostic of Hemolytic anemia, acute leukemia, chronic myelocytic leukemia, chronic Lymphocytic leukemia, nutritional anemia, malaria, and can be helpful in some other disorders.

Reticulocyte count is another to give us a good idea about bone marrow activities. In this respect, the differentials can also help in suggesting some other disorders like infections, helminthiasis and others. To see the evidences in favour of hemolysis serum bilirubin can be done expecting it to rise. Direct agglutination test (DAT) can also give us the idea about immune etiology behind hemolysis.

If the diagnosis still remains inconclusive bone marrow can give us the final diagnosis of Leukemia (Acute or Chronic), infiltration of metastasis or storage disorder, any infectious diseases like malaria or kala-azar, aplastic or hypoplastic anemia, dyserythropoiesis and additionally bone marrow response to the anemia.

To know the etiology we may have to do some more investigations like Iron profile, vitamin B12, folate assay, schilling test, Radio assay of RBC life span, imaging, endoscopy, colonoscopy, $\mathrm{Hb}$ electrophoresis, OBT etc. ${ }^{16,17}$

\section{The diagnostic approach}

From the above discussion it has been clear that diagnosis of anemia requires a wide array of disease spectrum. Therefore, a definite diagnostic approach is necessary but difficult. Here, a diagnostic approach on the basis of clinical impression, is being proposed, that is as follows. 


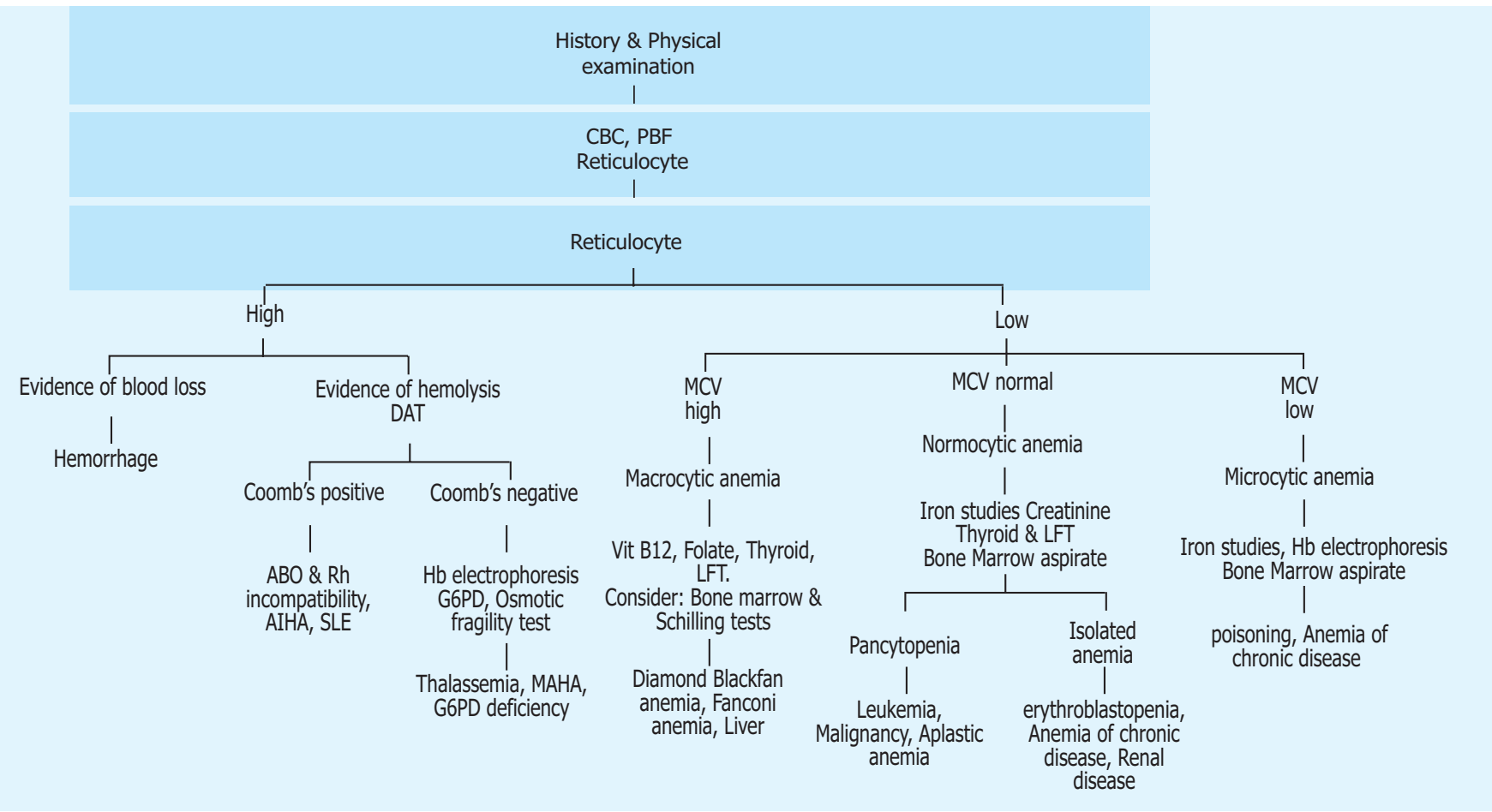

\section{conclusion}

Anemia is the manifestation of many diseases. Therefore, diagnosis of the disease is important. A rational diagnostic approach based on history and physical examination as well as stepwise lab support is very important. Besides differentials, crucial investigations are MCV, Reticulocyte count, bilirubin, DAT and $\mathrm{Hb}$ electrophoresis. A good drill through the clinical and laboratory procedures enables cliniciansidentify the cause of anemia and reach the diagnosis.

\section{References}

1. Judith M, Kren RR, Stuber CP, Poplack DG. Acute Lymphoblastic Leukemia. In: Pizo PA \& Poplack DG, editors. Principles and Practice of Pediatric Oncology. $6^{\text {th }}$ ed.Lipincott Williams and Wilkins. 2011;518-565.

2. World Health Organization, The World Health Report 2002: Reducing Risks, Promoting Healthy Life, World Health Organization, Geneva, Switzerland, 2002.

3. L. Allen, B. de Benoist, O. Dary, and R. Hurrell, Guidelines on Food Fortification with Micronutrients, WHO, Geneva, Switzerland, 2006.

4. R. K. Singh and S. Patra, "Extent of anaemia among preschool children in EAG states, India: a challenge to policy makers," Anemia 2014, Article ID 868752, 9 pages, 2014. View at Publisher ' View at Google Scholar · View at Scopus

5. Bolton-Maggs $P$, Thomas $A$. Disorders of the blood and bone marrow. In: McIntosh N, Helms PJ, Smyth RL, Logan S, editors. Forfar and Arneil Text books of Pediatrics. $7^{\text {th }}$ edition. Churchill Livingstone. 2008:959-990.

6. Morris Green. Pallor and Anemia Chapter 58. In: Pediatric Diagnosis. $6^{\text {th }}$ Edition. WB Saunders. 1998: 436.

7. Joo EY, Kim KY, Kim DH, Lee JE, Kim SK. Iron deficiency anemia in infancy and toddlers. Blood Research 2016. 51(4):268-273.
8. Watson HG, Graig JIO, Manson LM. Blood diseases. In: Walker BR, Colledge NR, Ralston SH, Penman ID, editors. Davidson's Principles \& Practice of Medicine. $22^{\text {nd }}$ ed. Churchill Livingstone. 2014:1990-1056.

9. Steele $M$, Narendran A. Mechanisms of defective erythropoiesis and anemia in pediatric acute lymphoblastic leukemia. Ann Hematol 2012;91(10):1513-1518.

10. Baist NRM, Steiner RD. Lysosomal storage disorders. In: Mc Intosh N, Helms PJ, Smyth RL, Logan S, editors. Forfar and Arneil's Textbook of Pediatrics. $7^{\text {th }}$ ed. Churchill Livingstone. 2008: 1101-1112.

11. Shimamura A, Guinan EC. Acquired aplastic anemia. In: Nathan DG, Oski SH, Ginsburg D, Look AT editors. Nathan and Oski's Hematology of Infancy and Childhood. $6^{\text {th }}$ ed. Saunders, Pennsylvania. 2003:256-279.

12. Freedman $\mathbf{M H}$, Doyle Jj. Inherited bone marrow failure syndromes. In: Lilleyman JS, Hnn IM, Blanchettte VS, editors. Pediatric Hematology. $2^{\text {nd }}$ ed. Churchill Livingstone.1999:23-49.

13. Weatherall DJ. Hemoglobin and inherited disorders of globin. In: Hoffbrand AV, Catovsky D, tuddenham EGD, editors. Postgraduate Hematology.Blackwell Publishing. 2005:85-103.

14. Blanc $L$, Wolfe LC. General considerations of hemolytic diseases, red cell membrane and enzyme defects. In: Lanzkowsky P, Lipton JM, Fish JD, editors. Lanzkowsky's manual of Pediatric Hematology and Oncology. $6^{\text {th }}$ ed. Eds. Academic Press. 2016:134-158.

15. Gordon-Smith EC, Marsh JCW. Acquired Hemolytic Anemias. In:Hoffbrand AV, Catovsky D, tuddenham EGD, editors. Postgraduate Hematology. Blackwell Publishing. 2005. Blackwell Publishing. 2005:151-167.

16. Leiner NB. The anemias. In: Kleigman RM, editor. Nelson textbook of Pediatrics. $19^{\text {th }}$ ed. Saunders. 2011:1648-1692.

17. Adamson JW, Longo DL. Anemia and Polycythemia. In: Longo DL, Fauci AS, Kasper DL, Hauser SL, Jameson JL, Loscalz OJ, editors. Harrison's Principle of Internal Medicine $18^{\text {th }}$ ed. Mc Graw Hill. 2012:448-457. 